\title{
Causes of Drug Abuse In Youth: Case of Mid-Western Region of
} Nepal

\section{Dhanush Chandra Pathak ${ }^{1}$ and Binod Pokharel ${ }^{2}$}

${ }^{1} \mathrm{PhD}$ Scholar, Mewar University, Chittorgarh, Rajasthan, India

${ }^{2}$ Research Supervisor, Professor, Tribhuvan University, Kathmandu, Nepal.

\section{Corresponding Author}

Dhanush Chandra Pathak

Email: pdhanushchandra@gmail.com

\begin{abstract}
Drug abuse is one of the serious social problems in Nepal and elsewhere for a long time. Drug abuse has several effects over the human life. Burgeoning unemployment, broken family, crime, depression, love failure, formation of peer group, mass media are major problems faced by the youth of the country. This paper explores the causes of drug abuse among youth in Mid-Western Region of Nepal. Quantitative research method was used to draw the data from 252 respondents. Simple random sampling technique was used to select the respondents of different rehabilitation center of Surkhet, Banke and Dang District. Data were analyzed by using chi-square statistical tools. Drug causes have covered the psychological, peer pressure, school/ college, socio cultural and mass media causes of drug abuse. Among them, majority respondent responded causes of drug abuse is bad relationship with family, to feel relax, failed in exam and films stars and idols which are shown on television.
\end{abstract}

\section{KEYWORDS}

Abuse, Cause, Drug, Mid-Western Region, Youth

\section{INTRODUCTION}

"Drug abuse" has been defined as any use of drugs for non-medical purposes almost always for altering consciousness. Drug abuse denotes substances that change the mental or physical state of a person and that may be used repeatedly for that effect leading to abnormality (Matowo, 2013, $\mathrm{p}$. 1). Global increasing in problems of illicit drugs both reflect and contribute to international tensions. The origins of some of these tensions are clear: rapid changes in political alignment, reduced family and community cohesiveness, increased unemployment and underemployment, economic and social marginalization and increased crime (UNDCP, 1995, p. 3). Drug and substance abuse has continued to ruin youth and subsequently education despite various measures taken to stop it (Njeri \& Ngesu, 2014, p. 1). As said by Grant (1990), causes of abusing drugs can be categorized into two parts i.e. internal and external causes. Under internal causes, it depends on 
the nature of drug and the personality. The consequences of any form of drug taking involve an interrelationship between the individual and his or her personality which may increase or decrease the vulnerability to drug abuse, and the characteristics of the drug consumed (Matowo, 2013, p. 20).

\section{METHODOLOGY}

This study was conducted in the Mid-Western development region of Nepal in 2016. Research was based on the descriptive research design. The simple random sampling technique was used to select the respondents. Total 256 male respondents were selected from the different sampled rehabilitation center of Surkhet, Dang and Banke district of Mid-Western region of Nepal using the observation and questionnaire survey. The result was drawn from the primary data and critically discussed with the secondary data. Secondary data were collected from published book, bulletin of Rehabilitation Centre. Frequency table and chi squire test were used to analyze the data by using the SPSS software.

\section{RESULTS AND DISCUSSIONS}

The data shows the different causes of drug abuse.

\section{Causes of drug abuse}

The prevalence of drugs in the community, pathological family background includes broken homes, illegitimate relationships, alcoholic parents or parent's involvement in antisocial and illegal activities, peer influence, imitation of film stars and teenage idols, media adverts like radio, TV, high ambition, urbanization and unemployment, ignorance of the dangers of illegal drug use and alienation that they feel isolated and want to belong (Abudu, 23rd - 25th July, 2008, pp. 5-6).

Table 1: Family causes of drug abuse

\begin{tabular}{|c|c|c|c|c|c|c|c|c|c|c|}
\hline & \multicolumn{6}{|c|}{ District } & \multirow{2}{*}{\multicolumn{2}{|c|}{ Total }} & \multirow{3}{*}{$\begin{array}{l}\text { Pearson } \\
\text { Chi-Square } \\
\text { (P value) }\end{array}$} \\
\hline & & \multicolumn{2}{|c|}{ Surkhet } & \multicolumn{2}{|c|}{ Banke } & \multicolumn{2}{|c|}{ Dang } & & & \\
\hline & & $\mathrm{N}$ & $\%$ & $\mathrm{~N}$ & $\%$ & $\mathrm{~N}$ & $\%$ & $\mathrm{~N}$ & $\%$ & \\
\hline \multirow{3}{*}{ 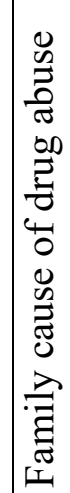 } & $\begin{array}{ll}\text { Death of } \\
\text { Family } \\
\text { member }\end{array}$ & 9 & 3.7 & 13 & 5.3 & 3 & 1.2 & 25 & 10.2 & .474 \\
\hline & $\begin{array}{l}\text { Separation } \\
\text { of Parents. }\end{array}$ & 5 & 2.0 & 3 & 1.2 & 1 & 0.4 & 9 & 3.7 & .683 \\
\hline & $\begin{array}{l}\text { Father or } \\
\text { mother did } \\
\text { second } \\
\text { marriage }\end{array}$ & 4 & 1.6 & 4 & $1.6 \%$ & 2 & 0.8 & 10 & 4.1 & .973 \\
\hline
\end{tabular}

Vol. 4. No. II

www.phdcentre.edu.np 


\begin{tabular}{|l|l|l|l|l|l|l|l|l|l|l|}
\hline & $\begin{array}{l}\text { Bad } \\
\text { relationship } \\
\text { with family }\end{array}$ & 39 & 16.0 & 42 & 17.2 & 14 & 5.7 & 95 & 38.9 & .668 \\
\hline $\begin{array}{l}\text { Parents fails } \\
\text { to fulfill } \\
\text { needs }\end{array}$ & 20 & 8.2 & 12 & 4.9 & 7 & 2.9 & 39 & 16.0 & .335 \\
\hline $\begin{array}{l}\text { Enough } \\
\text { pocket } \\
\text { money }\end{array}$ & 23 & 9.4 & 31 & 12.7 & 18 & 7.4 & 72 & 29.5 & .114 \\
\hline $\begin{array}{l}\text { Parents also } \\
\text { take drug }\end{array}$ & 13 & 5.3 & 3 & 1.2 & 0 & 0.0 & 16 & 6.6 & .003 \\
\hline $\begin{array}{l}\text { Bad } \\
\text { relation } \\
\text { with spouse }\end{array}$ & 4 & 1.6 & 5 & 2.0 & 0 & 0.0 & 9 & 3.7 & .465 \\
\hline Total
\end{tabular}

Sources: Field survey, 2016

Table 1 shows the results of family causes of drug abuse. $38.9 \%$ respondents said they started drug because of bad relationship with family, 29.5\% said because they had enough pocket money, $16.0 \%$ said parents fail to fulfill needs, likewise $10.2 \%$ said family member died, $6.6 \%$ said parents also take drug, $4.1 \%$ said father or mother did second marriage, $3.7 \%$ said parents separated and the same percent said bad relation with spouse.

Out of 103 respondents from Surkhet district, 16.0\% said bad relationship with family, 9.4 $\%$ said they started using drug because they had enough pocket money, $8.2 \%$ said parents fail to fulfill their needs, likewise, 5.3\% said parents also take drug, similarly, 3.7\% said family member died, $2.0 \%$ said parents separated, $2 \%$ replied father or mother did second marriage, and the same percent said bad relation with spouse. Similarly, among 99 respondents from Banke district, $17.2 \%$ said bad relationship with family, $12.7 \%$ said they started using drug because they had enough pocket money, 5.3\% said parents family member died., likewise $4.9 \%$ said parents fail to fulfill needs, $2.0 \%$ said bad relation with spouse., $1.6 \%$ said father or mother did second marriage, family member died and parents also take drug had equal responses, i.e. 1.2. \%,. Likewise, from Dang district, out of 42 respondents, 7.4\% said enough pocket money, $5.7 \%$ said bad relationship with family, $2.9 \%$ said parents fail to fulfill their needs, likewise $1.2 \%$ said family member died, $0.8 \%$ said father or mother did second marriage, $0.4 \%$ said parents separated, there were no responses for parents also take drug and bad relation.

Death of family member as family causes of drug abuse in three districts the statistical analysis of Pearson Chi-Square test found that there is no significant association because the $\mathrm{P}=$ .474 which is higher than .05 significant level. Separation of parents as family causes of drug abuse in three districts there is no significant association because the $\mathrm{P}=.683$ which is bigger than .05 significant level. Regarding second marriage or parents as family causes of drug abuse in three districts, the statistical analysis of Pearson Chi-Square test found that there is no significant 
association because the $\mathrm{P}=.683$ which is bigger than .05 significant level. Bad relationship with family as family causes of drug abuse in three districts there is no significant association because the $\mathrm{P}=.668$ which is bigger than .05 significant level. Parents fail to fulfil the need of respondents as family causes of drug abuse in three districts there is no significant association because the $\mathrm{P}=$ .335 which is bigger than .05 significant level. Enough pocket money as family causes of drug abuse in three districts there is no significant association because the $\mathrm{P}=.114$ which is bigger than .05 significant level. Parents also take drug as a family causes of drug abuse in three districts the statistical analysis of Pearson Chi-Square test found that there is significant association because the $\mathrm{P}=.003$ which is smaller than .05 significant level. Bad relationship with spouse as family causes of drug abuse in three districts there is no significant association because the $\mathrm{P}=.465$ which is bigger than .05 significant level.

Table 2: Psychological cause of drug abuse

\begin{tabular}{|c|c|c|c|c|c|c|c|c|c|c|}
\hline & \multicolumn{6}{|c|}{ District } & \multirow{2}{*}{\multicolumn{2}{|c|}{ Total }} & \multirow{3}{*}{$\begin{array}{l}\text { Pearson } \\
\text { Chi-Square } \\
\text { (P value) }\end{array}$} \\
\hline & & \multicolumn{2}{|c|}{ Surkhet } & \multicolumn{2}{|c|}{ Banke } & \multicolumn{2}{|c|}{ Dang } & & & \\
\hline & & $\mathrm{N}$ & $\%$ & $\mathrm{~N}$ & $\%$ & $\mathrm{~N}$ & $\%$ & $\mathrm{~N}$ & $\%$ & \\
\hline \multirow{3}{*}{ 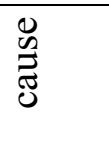 } & To feel intoxicated & 29 & 11.6 & 20 & 8.0 & 8 & 3.2 & 57 & 22.7 & .276 \\
\hline & To feel relax & 66 & 26.3 & 72 & 28.7 & 34 & 13.5 & 172 & 68.5 & .151 \\
\hline & To improve sleep & 20 & 8.0 & 21 & 8.4 & 3 & 1.2 & 44 & 17.5 & .135 \\
\hline \multirow{2}{*}{ 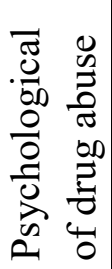 } & $\begin{array}{lr}\text { To } & \text { decrease } \\
\text { worrying } & \text { about } \\
\text { personal problems }\end{array}$ & 29 & 11.6 & 29 & 11.6 & 20 & 8.0 & 78 & 31.1 & .053 \\
\hline & To avoid loneliness & 17 & 6.8 & 15 & 6.0 & 11 & 4.4 & 43 & 17.1 & .250 \\
\hline \multicolumn{2}{|l|}{ Total } & 105 & 41.8 & 103 & 41.0 & 43 & 17.1 & 251 & 100.0 & \\
\hline
\end{tabular}

Sources: Field survey, 2016

Table 2 shows responses for the psychological causes of drug abuse majority $68.5 \%$ said they used drug to feel relax, $31.1 \%$ said they started using drug to decrease worrying about personal problems, similarly $22.7 \%$ said to feel intoxicated, $17.5 \%$ said to improve sleep, likewise $17.1 \%$ said to avoid loneliness. Drug gives temporal relaxation in the mind that is why majority respondents used drug to feel relax.

As a district wise distribution, out of 105 respondents from Surkhet district, $26.3 \%$ said to feel relax, to feel intoxicated, $11.6 \%$ said to decrease worrying about personal problems, similarly, $8.0 \%$ said to improve sleep, and $6.8 \%$ said to avoid loneliness. Similarly, from Banke district, out of 103 respondents, $28.7 \%$ said to feel relax as a psychological cause of drug abuse, $11.6 \%$ to decrease worrying about personal problems, likewise $8.4 \%$ said to improve sleep, $8.0 \%$ said to feel intoxicated, and $6.0 \%$ said to avoid loneliness. From Dang district out of 43 respondents, $13.5 \%$ said to feel relax as a psychological cause of drug abuse, $8.0 \%$ said to decrease worrying about personal problems, similarly $4.4 \%$ said to avoid loneliness, $3.2 \%$ said to feel intoxicated and $1.2 \%$ said to improve sleep. 
To feel intoxicated as a psychological cause of drug abuse in three districts the statistical analysis of Pearson Chi-Square test found that there is no significant association because the $\mathrm{P}=$ .276 which is bigger than .05 significant level. To feel relax as a psychological cause of drug abuse in three districts there is no significant association because the $\mathrm{P}=.151$ which is bigger than .05 significant level. To improve sleep as a psychological cause of drug abuse in three districts there is no significant association because the $\mathrm{P}=.135$ which is bigger than .05 significant level. To decrease worry as a psychological cause of drug abuse in three districts there is no significant association because the $\mathrm{P}=.053$ which is bigger than .05 significant level. To avoid loneliness as a psychological cause of drug abuse in three districts there is no significant association because the $\mathrm{P}=.250$ which is bigger than .05 significant level.

Table3: Peer pressure and influence cause of drug abuse

\begin{tabular}{|c|c|c|c|c|c|c|c|c|c|c|}
\hline & \multicolumn{6}{|c|}{ District } & \multirow{2}{*}{\multicolumn{2}{|c|}{ Total }} & \multirow{3}{*}{$\begin{array}{l}\text { Pearson } \\
\text { Chi-Square } \\
\text { (P value) }\end{array}$} \\
\hline & & \multicolumn{2}{|c|}{ Surkhet } & \multicolumn{2}{|c|}{ Banke } & \multicolumn{2}{|c|}{ Dang } & & & \\
\hline & & $\mathrm{N}$ & $\%$ & $\mathrm{~N}$ & $\%$ & $\mathrm{~N}$ & $\%$ & $\mathrm{~N}$ & $\%$ & \\
\hline \multirow{5}{*}{ 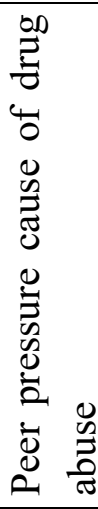 } & $\begin{array}{l}\text { Did not want to } \\
\text { stand out from the } \\
\text { group }\end{array}$ & 8 & 3.2 & 20 & 8.0 & 5 & 2.0 & 33 & 13.2 & .024 \\
\hline & $\begin{array}{ll}\begin{array}{l}\text { Couldn't deny } \\
\text { peers }\end{array} & \\
\end{array}$ & 33 & 13.2 & 45 & 18.0 & 26 & 10.4 & 104 & 41.6 & .003 \\
\hline & Peers forced & 25 & 10.0 & 21 & 8.4 & 3 & 1.2 & 49 & 19.6 & .069 \\
\hline & Give company & 27 & 10.8 & 47 & 18.8 & 12 & 4.8 & 86 & 34.4 & .026 \\
\hline & $\begin{array}{l}\text { Have good time } \\
\text { with friends }\end{array}$ & 52 & 20.8 & 40 & 16.0 & 17 & 6.8 & 109 & 43.6 & .254 \\
\hline \multicolumn{2}{|l|}{ Total } & 105 & 42.0 & 103 & 41.2 & 42 & 16.8 & 250 & 100.0 & \\
\hline
\end{tabular}

Sources: Field survey, 2016

Table 3 shows that $43.6 \%$ responded used drug because they wanted to have good time with their friends, $41.6 \%$ replied they could not deny their peers, like wise $34.4 \%$ said they used drug to give company, $19.6 \%$ said that they used drug because peers forced them and $13.2 \%$ said they did not want to stand out from the group.

Out of 105 respondents from Surkhet district, $20.8 \%$ said to have good time, $13.2 \%$ replied they could not deny peers, similarly, $10.8 \%$ said to give company, $10.0 \%$ said peers forced and $3.2 \%$ replied did not want to stand out from the group. Similarly, out of 103 respondents from Bake district, $18.8 \%$ said to give company, $18.0 \%$ said couldn't deny their peers, followed by $16.0 \%$ said to have good time, $8.4 \%$ replied peers forced and $8.0 \%$ said did not want to stand out from the group. From Dang district, out of 42 respondents, $10.4 \%$ responded could not deny my peers, $6.8 \%$ responded to have good time, similarly $4.8 \%$ said give company, $2.0 \%$ said did not want to stand out from the group and $1.2 \%$ said peers forced to take drug.

Do not want to stand out from the group as a peer pressure cause of drug abuse in three 
districts the statistical analysis of Pearson Chi-Square test found that there is significant association because the $\mathrm{P}=.024$ which is less than .05 significant level. Cannot deny friends as a peer pressure cause of drug abuse in three districts there is significant association because the $\mathrm{P}=.003$ which is smaller than .05 significant level. Peer force as a peer pressure cause of drug abuse in three districts there is no significant association because the $\mathrm{P}=.069$ which is bigger than .05 significant level. Give company to friend as a peer pressure cause of drug abuse in three districts the statistical analysis of Pearson Chi-Square test found that there is significant association because the $\mathrm{P}=.026$ which is smaller than .05 significant level. Have good time with friends as a peer pressure cause of drug abuse in three districts there is no significant association because the $\mathrm{P}=.254$ which is bigger than .05 significant level.

People see family members, friends, role models or entertainers using drugs and rationalize that they can too. The Report of Central Bureau of Statistics reported that peer pressure is the major cause reported for drug intake (78.7\%).Curiosity accounted to 58.5\% and family problem $19.9 \%$. (Government of Nepal Central Bureau of Statistics, 2014, p. 22).

Table 4: School/ college environment cause of drug abuse

\begin{tabular}{|c|c|c|c|c|c|c|c|c|c|c|}
\hline & \multicolumn{6}{|c|}{ District } & \multirow{2}{*}{\multicolumn{2}{|c|}{ Total }} & \multirow{3}{*}{$\begin{array}{l}\text { Pearson } \\
\text { Chi-Square } \\
\text { (P value) }\end{array}$} \\
\hline & & \multicolumn{2}{|c|}{ Surkhet } & \multicolumn{2}{|c|}{ Banke } & \multicolumn{2}{|c|}{ Dang } & & & \\
\hline & & $\mathrm{N}$ & $\%$ & $\mathrm{~N}$ & $\%$ & $\mathrm{~N}$ & $\%$ & $\mathrm{~N}$ & $\%$ & \\
\hline \multirow{2}{*}{ 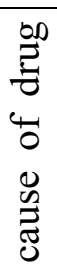 } & $\begin{array}{ll}\text { Difficult } & \text { to } \\
\text { adjust } & \text { in } \\
\text { school } & \end{array}$ & 15 & 6.1 & 12 & 4.9 & 9 & 3.6 & 36 & 14.6 & .317 \\
\hline & $\begin{array}{l}\text { Failed in the } \\
\text { exam. }\end{array}$ & 34 & 13.8 & 45 & 18.2 & 12 & 4.9 & 91 & 36.8 & .138 \\
\hline \multirow{2}{*}{ 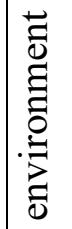 } & $\begin{array}{l}\text { Teachers' } \\
\text { discrimination }\end{array}$ & 5 & 2.0 & 7 & 2.8 & 1 & 0.4 & 13 & 5.3 & .542 \\
\hline & $\begin{array}{l}\text { Teachers' } \\
\text { punishment }\end{array}$ & 10 & 4.0 & 14 & 5.7 & 2 & 0.8 & 26 & 10.5 & .274 \\
\hline \multirow{2}{*}{ 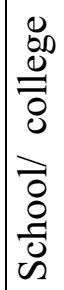 } & $\begin{array}{l}\text { Easy to get } \\
\text { drug at school }\end{array}$ & 43 & 17.4 & 43 & 17.4 & 23 & 9.3 & 109 & 44.1 & .301 \\
\hline & $\begin{array}{l}\text { Lack of extra } \\
\text { activities in } \\
\text { the school }\end{array}$ & 8 & 3.2 & 14 & 5.7 & 5 & 2.0 & 27 & 10.9 & .395 \\
\hline \multicolumn{2}{|c|}{ Total } & 103 & 41.7 & 103 & 41.7 & 41 & 16.6 & 247 & 100.0 & \\
\hline
\end{tabular}

Sources: Field survey, 2016

Table 4 shows $44.1 \%$ responded easy to get drug at schools, $36.8 \%$ responded used drug because they failed in exam, like wise $14.6 \%$ said difficult to adjust in school, $10.9 \%$ said lack of extra activities in the school, and $10.5 \%$ said teachers' punishment and $5.3 \%$ said teachers' 
discrimination.

Out of 103 respondents from Surkhet district, $17.4 \%$ responded easily to get drug at schools, $13.8 \%$ responded failed in the exam, $6.1 \%$ replied difficult to adjust in school, $4.0 \%$ said teachers' punishment, similarly 3.2\% said lack of extra activities in the school and minority $2.0 \%$ said teachers' discrimination. Likewise, from Banke district, among 103 respondents, 18.2\% responded failed in the exam, $17.4 \%$ responded easily to get drug at school, lack of extra activities in the school and teachers' punishment had equally 5.7\%, similarly, $6.1 \%$ said difficult to adjust in school and 2.8\% said teachers' discrimination. Similarly, out of 41 respondents from Dang district, $9.3 \%$ responded easy to get drug at schools, $4.9 \%$ responded failed in the exam, 3.6\% replied difficult to adjust in school, $2.0 \%$ said lack of extra activities in the school, $0.8 \%$ said Teachers' punishment and minority $0.4 \%$ said teachers' discrimination.

Difficult to adjust in school as school/college cause of drug abuse in three districts the statistical analysis of Pearson Chi-Square test found that there is no significant association because the $\mathrm{P}=.317$ which is bigger than .05 significant level. Fail in exam as school/college cause of drug abuse in three districts there is no significant association because the $\mathrm{P}=.138$ which is bigger than .05 significant level. Teacher's discrimination as school/college cause of drug abuse in three districts the statistical analysis of Pearson Chi-Square test found that there is no significant association because the $\mathrm{P}=.542$ which is bigger than .05 significant level. Punishment as school/college cause of drug abuse in three districts there is no significant association because the $\mathrm{P}=.274$ which is bigger than .05 significant level. Easy to get drug at school/college as school/college cause of drug abuse in three districts there is no significant association because the $\mathrm{P}=.301$ which is bigger than .05 significant level. Lack of extra activities as school/college cause of drug abuse in three districts the statistical analysis of Pearson Chi-Square test found that there is no significant association because the $\mathrm{P}=.395$ which is bigger than .05 significant level.

Various previous literature has also shown the availability of drug within the premises of school; students use drug. In this connection, drug users were asked about their school environment which might cause their involvement in drug use. Schools also provide opportunities for young people to have contact with others who may have differing or similar expectations about substance use, as well as offer the potential for access to substances (Kirby, Sluijs, \& Inchley, 2008, p. 42).

Table 5: Social and cultural cause of drug abuse

\begin{tabular}{|c|c|c|c|c|c|c|c|c|c|c|}
\hline & \multicolumn{6}{|c|}{ District } & \multirow{2}{*}{\multicolumn{2}{|c|}{ Total }} & \multirow{3}{*}{$\begin{array}{l}\text { Pearson } \\
\text { Chi- } \\
\text { Square (P } \\
\text { value) }\end{array}$} \\
\hline & & \multicolumn{2}{|c|}{ Surkhet } & \multicolumn{2}{|c|}{ Banke } & \multicolumn{2}{|c|}{ Dang } & & & \\
\hline & & $\mathrm{N}$ & $\%$ & $\mathrm{~N}$ & $\%$ & $\mathrm{~N}$ & $\%$ & $\mathrm{~N}$ & $\%$ & \\
\hline $\begin{array}{l}\bar{\delta} \\
\delta\end{array}$ & $\begin{array}{l}\text { Neighbours } \\
\text { also take drug }\end{array}$ & 18 & 7.2 & 38 & 15.3 & 8 & 3.2 & 64 & 25.7 & .003 \\
\hline
\end{tabular}




\begin{tabular}{|l|l|l|l|l|l|l|l|l|l|}
\hline $\begin{array}{l}\text { Drug is } \\
\text { common in my } \\
\text { culture }\end{array}$ & 25 & 10.0 & 17 & 6.8 & 7 & 2.8 & 49 & 19.7 & .471 \\
\hline $\begin{array}{l}\text { Prevalence of } \\
\text { drugs in the } \\
\text { community }\end{array}$ & 25 & 10.0 & 34 & 13.7 & 9 & 3.6 & 68 & 27.3 & .357 \\
\hline $\begin{array}{l}\text { Discrimination } \\
\text { of caste or } \\
\text { ethnicity }\end{array}$ & 6 & 2.4 & 7 & 2.8 & 2 & 0.8 & 15 & 6.0 & .881 \\
\hline $\begin{array}{l}\text { Don't } \\
\text { remember }\end{array}$ & 37 & 14.9 & 26 & 10.4 & 19 & 7.6 & 82 & 32.9 & .058 \\
\hline Total & 104 & 41.8 & 102 & 41.0 & 43 & 17.3 & 249 & 100.0 & \\
\hline
\end{tabular}

Sources: Field survey, 2016

Table 5 explores that $32.9 \%$ responded don't remember about the social and culture causes of drug abuse, $27.3 \%$ responded prevalence of drugs in the community; similarly, $25.7 \%$ said neighbors also take drug, $19.7 \%$ said drug is common in my culture and $6.0 \%$ said discrimination of caste or ethnicity in the society.

As district wise distribution of Social and Cultural Causes of Drug Abuse, from Surkhet district, out of 104 respondents, $14.9 \%$ responded do not remember about the social and culture causes of drug abuse, drug is common in my culture and prevalence of drugs in the community had equally second majority $10.0 \%$, similarly $7.2 \%$ replied neighbours also take drug and $2.4 \%$ replied discrimination of caste or ethnicity in the society. Likewise, from Banke district, $15.3 \%$ responded neighbours also take drug as the social and culture causes of drug abuse, second majority $13.7 \%$ said prevalence of drugs in the community, followed by $10.4 \%$ don't remember, $6.8 \%$ said drug is common in their culture and $2.4 \%$ said discrimination of caste or ethnicity in the society. Similarly, from Dang district $7.6 \%$ responded don't remember about the social and culture causes of drug abuse, $3.6 \%$ responded prevalence of drugs in the community, followed by $3.2 \%$ neighbors also take drug, $2.8 \%$ said drug is common in their culture and $0.8 \%$ said discrimination of caste or ethnicity in the society.

Neighbors involvement as social and cultural causes of drug abuse in three districts the statistical analysis of Pearson Chi-Square test found that there is significant association because the $\mathrm{P}=.003$ which is smaller than .05 significant level. Drug is common in their culture as social and cultural causes of drug abuse in three districts there is no significant association because the $P$ $=.471$ which is bigger than .05 significant level. Prevalence of drug in community as Social and cultural causes of drug abuse in three districts there is no significant association because the $\mathrm{P}=$ .357 which is bigger than .05 significant level. Discrimination of caste or ethnicity in the society as social and cultural causes of drug abuse in three districts there is no significant association because the $\mathrm{P}=.881$ which is bigger than .05 significant level. Do not remember as social and cultural causes of drug abuse in three districts there is no significant association because the $\mathrm{P}=$ .058 which is bigger than .05 significant levels. 
Values may be influenced by multiple factors including social, religious, and personal views. Especially among contemporary youths, many individuals struggle to relate to peers. The stress of socializing can be a major reason why individuals turn to intoxicants as a means of curbing social anxiety. Another social factor that contributes to addiction is the tendency for drug and alcohol abuse to promote group solidarity and feelings of community and belonging (O'Leary, 2014).

Table 6: Mass media cause of drug abuse

\begin{tabular}{|c|c|c|c|c|c|c|c|c|c|c|}
\hline & \multicolumn{6}{|c|}{ District } & \multirow{2}{*}{\multicolumn{2}{|c|}{ Total }} & \multirow{3}{*}{$\begin{array}{l}\text { Pearson } \\
\text { Chi-Square } \\
\text { (P value) }\end{array}$} \\
\hline & & \multicolumn{2}{|c|}{ Surkhet } & \multicolumn{2}{|c|}{ Banke } & \multicolumn{2}{|c|}{ Dang } & & & \\
\hline & & $\mathrm{N}$ & $\%$ & $\mathrm{~N}$ & $\%$ & $\mathrm{~N}$ & $\%$ & $\mathrm{~N}$ & $\%$ & \\
\hline \multirow{4}{*}{ 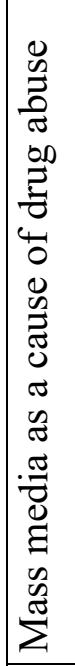 } & $\begin{array}{lr}\text { Imitation of } \\
\text { films stars and } \\
\text { idol } & \text { which } \\
\text { shown } & \text { on } \\
\text { television } & \end{array}$ & 17 & 6.9 & 36 & 14.7 & 16 & 6.5 & 69 & 28.2 & .002 \\
\hline & \begin{tabular}{|l} 
Media \\
advertisements
\end{tabular} & 15 & 6.1 & 16 & 6.5 & 2 & 0.8 & 33 & 13.5 & .201 \\
\hline & $\begin{array}{l}\text { Drug users life } \\
\text { style shown on } \\
\text { the television }\end{array}$ & 23 & 9.4 & 30 & 12.2 & 12 & 4.9 & 65 & 26.5 & .380 \\
\hline & $\begin{array}{l}\text { Don't } \\
\text { remember }\end{array}$ & 55 & 22.4 & 31 & 12.7 & 16 & 6.5 & 102 & 41.6 & .005 \\
\hline \multicolumn{2}{|c|}{ Total } & 105 & 42.9 & 100 & 40.8 & 40 & 16.3 & 245 & 100.0 & \\
\hline
\end{tabular}

Sources: Fieldsurvey, 2016

Table 6 revealed that $41.6 \%$ respondents responded do not remember about mass media which causes drug abuse, $28.2 \%$ said imitation of films stars and idols which are shown on television, followed by $26.5 \%$ drug users were influenced by life styles shown on the television and $13.5 \%$ said media advertisements.

From Surkhet district, $22.4 \%$ respondents showed their anonymity about mass media as the cause of drug abuse, followed by $9.4 \%$ said drug users' life style shown on the television, $6.9 \%$ said imitation of films stars and idols which are shown on television and $6.1 \%$ said media advertisements. Similarly, from Banke district, 14.7\% respondents responded imitation of films stars and idols which are shown on television about mass media causes of drug abuse followed by $12.7 \%$ respondents showed anonymity, $12.2 \%$ said drug users' life style shown on the television and $6.5 \%$ said media advertisements as mass media causing to be drug abuser. From Dang district, $6.5 \%$ responded equally imitation of films stars and idols which are shown on television and anonymity, followed by $4.9 \%$ said drug users' life style shown on the television and $0.8 \%$ responded media advertisements as mass media causes of drug abuse. 
Imitation of films stars and idol which shown on television as a mass media causes of drug abuse in three districts the statistical analysis of Pearson Chi-Square test found that there is significant association because the $\mathrm{P}=.002$ which is smaller than .05 significant levels. Media advertisement as a mass media causes of drug abuse in three districts there is no significant association because the $\mathrm{P}=.201$ which is bigger than .05 significant level. Drug users life style shown on the television as a mass media causes of drug abuse in three districts there is no significant association because the $\mathrm{P}=.380$ which is bigger than .05 significant levels. Don't remember as a mass media causes of drug abuse in three districts the statistical analysis of Pearson Chi-Square test found that there is significant association because the $\mathrm{P}=.005$ which is smaller than .05 significant levels.

Digital media are increasingly being used to advertise drugs. While generations of old experienced the advent of television and the advent of the internet, technology's rapid evolution over the last several decades has profoundly affected the world we live in. Teens are using drugs as early as middle school, and technology is making this easier than ever. Recent studies show that $75 \%$ of teenagers seeing photos on social networks of other teens smoking weed or drinking encourages them to party in the same way (Teen Rehab Center, 2016).

\section{CONCLUSIONS}

Socio-economic background of the family, psychological, peer pressure, school/college, socio culture and mass media causes of drug abuse. The study found that bad relationship with family as a family cause of drug abuse, similarly youth use drug abuse to feel relax as a psychological cause of drug. Not only that study explored youth used drug to have good time with friends as peer pressure and influence cause. Majority respondent responded they start drug because they failed in exam as a school/ college environment of cause. As a mass media cause majority respondents said they start drug because films stars and idols which are shown on television.

\section{ACKNOWLEDGEMENT}

We thankfully acknowledge to Mr. Amrit Kumar Sharma Gaire his close supervision during research and we are also thankful to Mewar University Rajasthan.

\section{REFERENCES}

Azuz, C. (2012). Study: Kids drink, do drugs at school. CNN.

DARA, T. (2008). www.alcohol rehab.com. Retrieved July 7, 2017, from www.alcohol rehab.com: http://alcoholrehab.com/drug-addiction/age-and-substance-abuse/

Government of Nepal Central Bureau of Statistics. (2014). Survey Report on Current Hard Drug Users in Nepal - 2069. Bijulibazar, Kathmandu: Ministry of Home Affairs Drug Control Programme.

Kirby, J., Sluijs, W. V., \& Inchley, J. (2008). Young people and substance use the influence of 
personal, social and environmental factors on substance use among adolescents in Scotland. University of Edinburgh, Child and Adolescent Health Research Unit. Edinburgh: University of Edinburgh.

MATOWO, A. S. (2013). Cause, Effect and Remedial Measures of Drug Abuse Among the Children in Tanzania: A Case Study of Hananasifu Ward in Kinondoni District in Dar Es Salaam Region. Open University Of Tanzania, Social Work. Tanzania: Open University of Tanzania.

Njeri, N. A., \& Ngesu, L. (2014, May-June). Causes and Effects Of Drug and Substance Abuse Among Secondary School Students in Dagoretti Division, Nairobi West District-Kenya. Global Journal of Interdisciplinary Social Sciences, 3(3), 1-4.

O'Leary, D. (2014, April 15). rehabilitation process:rehabs.com. Retrieved February 24, 2017, from Rehabs.com: http://www.rehabs.com/5-socio-cultural-factors-that-cultivateaddiction/

Teen Rehab Center. (2016, August 24).webmaster@teenrehabcenter.org. Retrieved February 24, 2017, from www.Teen Rehab Center.com:

https://www.teenrehabcenter.org/resources/social-media-impact/

UNDCP. (1995). The Social Impact of Drug Abuse. Copenhagen: United Nations. 